\title{
Diagnostic Value of Fecal Calprotectin and Serum MMP-9 in Diagnosing Disease Activity of Ulcerative Colitis
}

\author{
Ali Ghweil, Mohamad Mounir, Ashraf Khodeary, Shereen Philip Aziz \\ Department of Clinical Pathology, Sohag Faculty of Medicine, Sohag University, Sohag, Egypt \\ Email: alimena1@yahoo.com, mohamad.mounir1981@gmail.com
}

How to cite this paper: Ghweil, A., Mounir, M., Khodeary, A. and Aziz, S.P. (2018) Diagnostic Value of Fecal Calprotectin and Serum MMP-9 in Diagnosing Disease Activity of Ulcerative Colitis. Open Journal of Gastroenterology, 8, 234-244.

https://doi.org/10.4236/ojgas.2018.86026

Received: March 8, 2018

Accepted: June 26, 2018

Published: June 29, 2018

Copyright (c) 2018 by authors and Scientific Research Publishing Inc. This work is licensed under the Creative Commons Attribution International License (CC BY 4.0).

http://creativecommons.org/licenses/by/4.0/

\begin{abstract}
Background and Study Aim: Ulcerative colitis (UC) is a chronic, idiopathic inflammatory bowel disease characterized by remission of disease activity. Searching for laboratory markers which are simple, sensitive, specific and non-invasive is fundamental to assess the extent of inflammation, activity of the disease, evolution and prognosis which can be used to assess response to treatment and the possibility of relapse. Our aim of the work was to investigate the diagnostic role of fecal calprotectin and serum MMP-9 in determining the activity of ulcerative colitis. Patients and Methods: 71 patients were included in the study and fecal calprotectin, serum MMP-9, ESR and CRP were measured in these patients to determine the disease activity of ulcerative colitis. Results: Fecal calprotectin concentration in the patients with active UC was significantly higher than that in inactive disease and in controls $(387.21 \pm 44.07 \mu \mathrm{g} / \mathrm{g}$ vs $103.62 \pm 119.67 \mu \mathrm{g} / \mathrm{g}, 12.44 \pm 3.65 \mu \mathrm{g} / \mathrm{g}, \mathrm{p}=0.000)$. Serum MMP-9 was found to be higher in patients with active UC than in patients with inactive disease $(11.02 \pm 5.29$ vs $4.01 \pm 1.72 \mathrm{ng} / \mathrm{ml}, \mathrm{p}=0.000)$. A significant difference was also found in the patients with active UC of mild, moderate and severe degrees. Also, strong positive correlation was found between fecal calprotectin and serum MMP-9 and the severity of the disease. The area under the curve of the receiver operating characteristics (AUCROC) was 0.949 and 0.941 for fecal calprotectin and serum MMP-9 respectively. Conclusion: Fecal calprotectin and serum MMP-9 can be used to differentiate between active and inactive forms of UC.
\end{abstract}

\section{Keywords}

Inflammatory Bowel Disease (IBD), Ulcerative Colitis (UC), Matrix Metalloproteinases (MMPs), Fecal Calprotectin (FC) 


\section{Introduction}

Ulcerative colitis (UC) is a chronic, idiopathic, inflammatory large bowel disease (IBD) with recurrent attacks of exacerbation. Determination of the disease activity is an essential part of clinical management [1]. Nowadays, the most accurate way to evaluate the severity of UC and extent of inflammation is colonoscopy and biopsy [2]. This procedure allows direct visualization of the large bowel, and the opportunity to take intestinal tissue samples for histopathological studies. Unfortunately, this is invasive, limited by cost, and requires an experienced operator as well as an often impossible preparatory regimen [3] [4]. Also, inter-observer variation in endoscopic evaluation of disease activity could change clinical outcomes, and have a fundamental impact on treatment options [5] [6].

On the other hand, patient symptoms cannot effectively reflect the extent of disease and response to treatment, nor are they a reliable index of healing of intestinal mucosa. Therefore, for evaluating the disease activity and therapeutic efficacy, a combination of monitoring symptoms with clinical, laboratory and endoscopic findings is used in routine clinical practice [7].

The diagnosis of UC is based on clinical symptoms combined with radiological and endoscopic investigations. Employment of non-invasive biomarkers is needed. Non-invasive biomarkers have the potential to avoid invasive diagnostic tests and inhibit potential complications [8]. These biomarkers can be divided into serological and fecal categories, [9] including erythrocyte sedimentation rate (ESR), C-reactive protein (CRP), platelet count, white blood cell count, interleukin-6, tumor necrosis factor-a (TNF-a), interleukin 1-b, and anti-neutrophil cytoplasmic antibody (ANCA) [10] [11].

Potentially, fecal markers have the advantage of possessing higher specificity for gastrointestinal diseases like IBD because the feces is in direct contact with colon mucosa and consequently contains special markers of mucosal disease [12]. Fecal calprotectin is one of these markers, it is a major protein in the neutrophilic granulocytes and the macrophages [13], which accounts for $60 \%$ of the total protein in the cytosol fraction in these cells [14] [15]. This kind of protein can resist metabolic degradation caused by intestinal bacteria, and the protein is relatively stable in stools for up to one week at room temperature [16]. It can differentiate between patients with organic or non-organic intestinal disease, and can be useful in detecting colorectal cancer and inflammatory disorders, and can also be useful in predicting a relapse of inflammatory bowel disease [10].

The human matrix metalloproteinases (MMPs) are a family of 24 zinc dependent endopeptidases. They are divided by domain structure and substrate preference into collagenases, gelatinases, stromelysins, and membrane type MMPs (MT-MMPs) [17]. The involvement of MMPs in inflammatory processes has been documented both in animal models with experimentally induced IBD and in intestinal cell lines as well as in cultures of inflammatory altered tissues [18]. MMP-9 has been demonstrated to be the main metalloproteinase implicated in the development of IBD [18] [19]. Recent studies suggest that it is epitheli- 
al-derived and not neutrophil-derived MMP-9 that is responsible for the penetration of inflammatory cells into inflamed tissue [18] [20]. The demonstration that the changes of MMPs on the organ level are reflected by their concentration or activity in easily accessible biological material would aid in the diagnosis and differentiation and monitoring of the course, as well as effectiveness of IBD treatment. We aimed through this work to investigate the diagnostic role of fecal calprotectin and serum MMP-9 in determining the activity of ulcerative colitis.

\section{Patients \& Methods}

The study included 71 patients ( 55 males and 16 females) divided into three groups including $24(33.8 \%)$ patients as control group, 23 (32.4\%) patients with inactive ulcerative colitis and $24(33.8 \%)$ patients with active disease with mean age $40 \pm 5$ years. Control group consisted of patients with no organic or metabolic disorders which were excluded on the basis of diagnostic procedures. The patients included into the control group were diagnosed with functional disorders such as functional dyspepsia, irritable bowel syndrome, and functional constipation. Patients were admitted in Tropical Medicine \& Gastroenterology Department, Qena Faculty of Medicine, South Valley University due to disease flare or for control examination. Patients with the coexistence of other severe systemic diseases, history of malignancy, liver diseases, or pregnancies were not included in our study.

Disease activity was estimated using Mayo score. This index, which combines clinical and endoscopic assessments, is the sum of scores from 4 components: stool frequency, rectal bleeding, sigmoidoscopic findings, and physician's global assessment. This disease activity index ranges from 0 to 12 and higher scores correlate with more advanced disease. In general, a patient is considered to be in remission if the Mayo score is 2 or below and to have severe disease if the score is above 10. Clinical response is generally accepted when the score decreases 3 points from the patient's initial baseline score [21].

Blood samples were drawn by venous puncture in a fasting state. Sera were obtained from clotted (30 min, room temperature) and centrifuged (15 min, 1500 $\times g)$ blood. Serum samples were stored at $-80^{\circ} \mathrm{C}$ until analysis. MMP-9 concentrations were estimated by Human ELISA Kit (abcam, United Kingdom). This assay employs an antibody specific for Human MMP9 coated on a 96-well plate. Standards and samples are drained into the wells and MMP9 present in a sample is attached to the wells by the immobilized antibody. Then we washed the wells and we added biotinylated anti-Human MMP9 antibody. After removing unbound biotinylated antibody, HRP-conjugated streptavidin is added to the wells. The wells are again washed, a TMB substrate solution is added to the wells and color appears in proportion to the amount of bound MMP9. The Stop Solution turns the color from blue to yellow, and the color intensity is measured at $450 \mathrm{~nm}$.

The stool samples were dissolved, and $50-100 \mathrm{mg}$ of the sample was suspended with 2500 - $5000 \mu \mathrm{L}$ of the fecal extraction buffer, and was homogenized; 
then, the suspernatant was diluted to 1:50, and the calprotectin was analyzed by ELISA kit (Eaglebioscinces, USA). Assay standards, controls and patient samples are added directly to wells of a microtiter plate that is coated with antibody to calprotectin. After a short incubation period, the plate is washed and horseradish peroxidase (HRP) conjugated human calprotectin specific monoclonal antibody is added to each well. After the second incubation period, a mixture of solid-phase antibody-human calprotectin-HRP conjugated monoclonal antibody" is formed. Then, we removed the buffer matrix and unbound monoclonal antibodies in the next step. For the detection of this immunocomplex, we incubated a substrate solution in a timed reaction and then measured in a spectrophotometric microplate reader at $450 \mathrm{~nm}$. Serum high-sensitive CRP was measured by the latex particle-enhanced immunoturbidimetric kit (Omega Diagnostics, UK). Data on hemoglobin, white blood cell count (WBC) and ESR were obtained from patients' medical records.

The study was approved by ethical committee of Qena Faculty of Medicine-South Valley University. Written informed consent was obtained from all patients before treatment.

\section{Statistical Analysis}

Data was analyzed using SPSS advanced statistics version 22 (SPSS Inc., Chicago, IL). Correlations between fecal CP, MMP-9, and clinical, endoscopic and histologic activity scores were determined by analysis of variance [ANOVA]. The p-value of equal to or less than 0.05 was considered statistically significant. The cut-off levels, sensitivity and specificity were calculated using the receiver operating characteristic [ROC] analysis. The cut-off level was calculated in the event that the value of the area under the ROC curve [AUC] was above 0.89 , determined by the maximum value of Youden's index [sensitivity + specificity-1].

\section{Results}

The demographic data of the studied patients presented in Table 1 included a mean age of $40 \pm 5$ years with male predominance (77.5\%). As regard to clinical activity of ulcerative colitis, $24(33.8 \%)$ patients presented with active attack while inactive state of ulcerative colitis was detected in 23 (32.4\%) patients. Based on Mayo score, mild disease was found in $37.5 \%$, moderate disease in $33.3 \%$ while severe ulcerative colitis was found in $29.2 \%$ of patients. Mean fecal calprotectin level was $150.35 \pm 173.58 \mu \mathrm{g} / \mathrm{g}$, mean serum MMP-9 was $5.54 \pm 5.18$ $\mathrm{ng} / \mathrm{ml}$, ESR $18.65 \pm 11.43 \mathrm{~mm} / \mathrm{h}$ and CRP $22.44 \pm 26.19 \mathrm{mg} / \mathrm{L}$.

Table 2 shows association between fecal calprotectin, serum MMP-9, CRP And ESR with clinical activity of ulcerative colitis, fecal calprotectin level in active ulcerative colitis was $387.21 \pm 44.07 \mu \mathrm{g} / \mathrm{g}$ which was higher than inactive $(103.62 \pm 119.67 \mu \mathrm{g} / \mathrm{g})$ or control group $(12.44 \pm 3.65 \mu \mathrm{g} / \mathrm{g})$ with statistically significant difference between active and inactive state $(p=0.000)$. Also, serum MMP-9 level in active ulcerative colitis was higher than inactive state of ulcerative 
Table 1. Characteristics of study population.

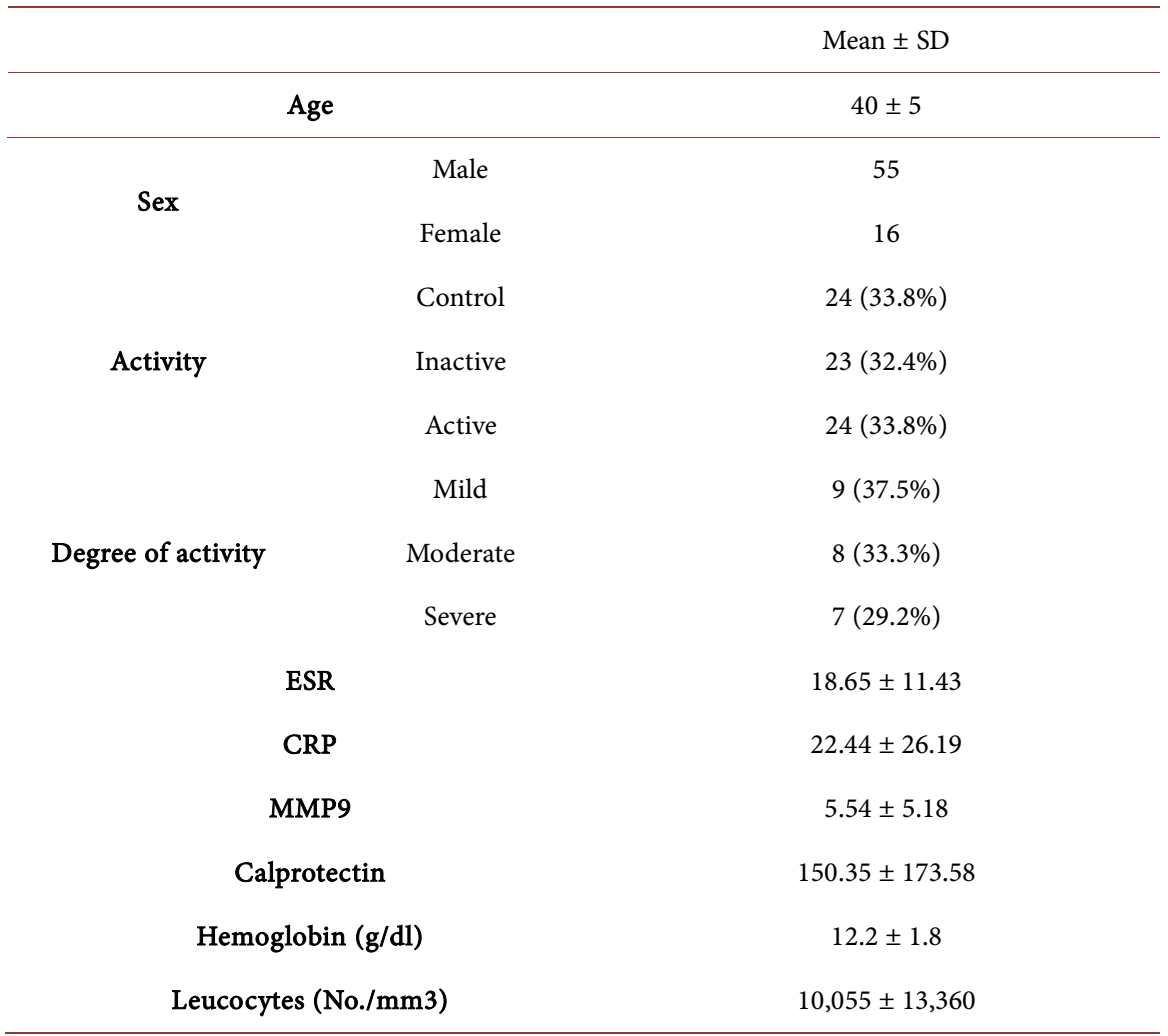

Table 2. Relation between laboratory investigations and clinical activity of ulcerative colitis.

\begin{tabular}{lccc}
\hline & \multicolumn{2}{c}{ Mean \pm SD } & p-value \\
\hline \multirow{2}{*}{ Calprotectin } & Control & $12.44 \pm 3.65$ & 0.000 \\
& Inactive & $103.62 \pm 119.67$ & \\
& Active & $387.21 \pm 44.07$ & 0.000 \\
MMP9 & Control & $1.53 \pm 0.65$ & \\
& Inactive & $4.01 \pm 1.72$ & \\
& Active & $11.02 \pm 5.29$ & 0.000 \\
CRP & Control & $2.64 \pm 0.59$ & \\
& Inactive & $16.04 \pm 15.57$ & 0.005 \\
& Active & $48.38 \pm 26.52$ & \\
\hline
\end{tabular}

colitis $(11.02 \pm 5.29$ vs $4.01 \pm 1.72 \mathrm{ng} / \mathrm{ml})(\mathrm{p}=0.000)$. CRP and ESR was significantly higher in active ulcerative colitis $(\mathrm{p}=0.000$ and $\mathrm{p}=0.005$ respectively) than in inactive or control group. 
Fecal calprotectin was found to have a strong positive correlation with the degree of activity of ulcerative colitis $(p=0.000)$ (Figure 1$)$. Serum MMP-9 varied significantly with the degree of activity of ulcerative colitis with elevated levels in more severe degrees of ulcerative colitis compared to moderate or mild degrees of severity and a significant positive correlation was found between serum MMP-9 and the degree of activity of ulcerative colitis $(\mathrm{p}=0.000)$ (Figure 2$)$.

On the other hand, CRP and ESR did not show significant correlation with the activity of ulcerative colitis.

The ROC curve is used to select the right cut-off point and to compare the diagnostic values of two or more diagnostic tests. The ROC analysis on the fecal calprotectin showed that a cut-off point of $240 \mu \mathrm{g} / \mathrm{g}$ had a $100 \%$ sensitivity and a 86.9\% specificity for making a differentiation between active UC and inactive UC. As regard to serum MMP-9, a cutoff value of $4.5 \mathrm{ng} / \mathrm{ml}$ had $100 \%$ sensitivity and a $82.6 \%$ specificity to differentiate between active and inactive UC (Figure 3 ).

\section{Discussion}

UC is a chronic, relapsing disease characterized by diffuse mucosal inflammation of the colon [22]. The precise etiology of UC is unknown; however, it is thought to be caused by an inappropriate inflammatory response to the gut contents in genetically predisposed individuals [23] [24]. The incidence and prevalence of ulcerative colitis have been increasing over time worldwide [25].

The diagnosis of UC is based on clinical symptoms combined with radiological and endoscopic investigations. Employment of non-invasive biomarkers is needed. Non-invasive biomarkers have the potential to avoid invasive diagnostic tests and inhibit potential complications [26].

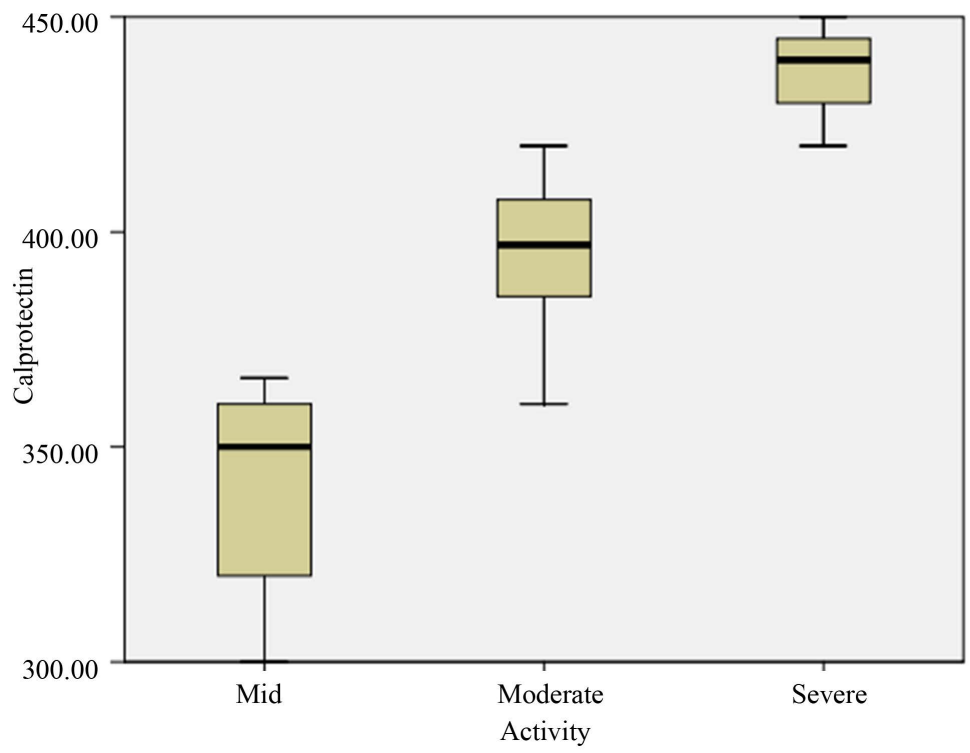

Figure 1. Correlation between fecal calprotectin $(\mu \mathrm{g} / \mathrm{g})$ and severity of ulcerative colitis. Fecal calprotectin was found to have a strong positive correlation with the degree of activity of ulcerative colitis. 


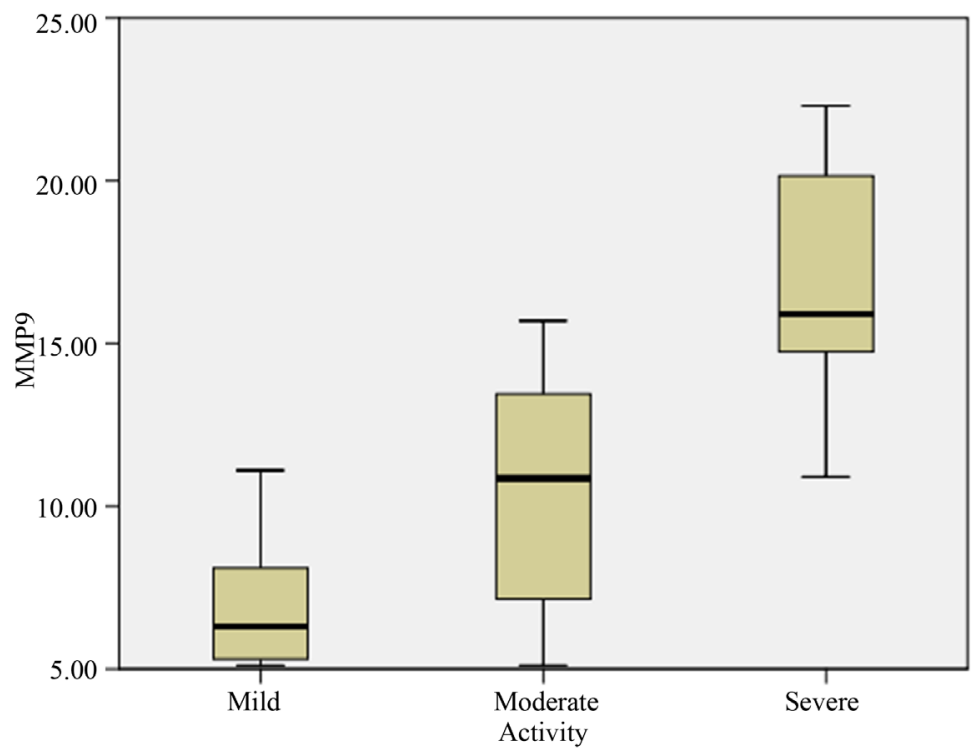

Figure 2. Correlation between serum MMP-9 (ng/ml) and severity of ulcerative colitis. A significant positive correlation was found between serum MMP-9 and the degree of activity of ulcerative colitis.

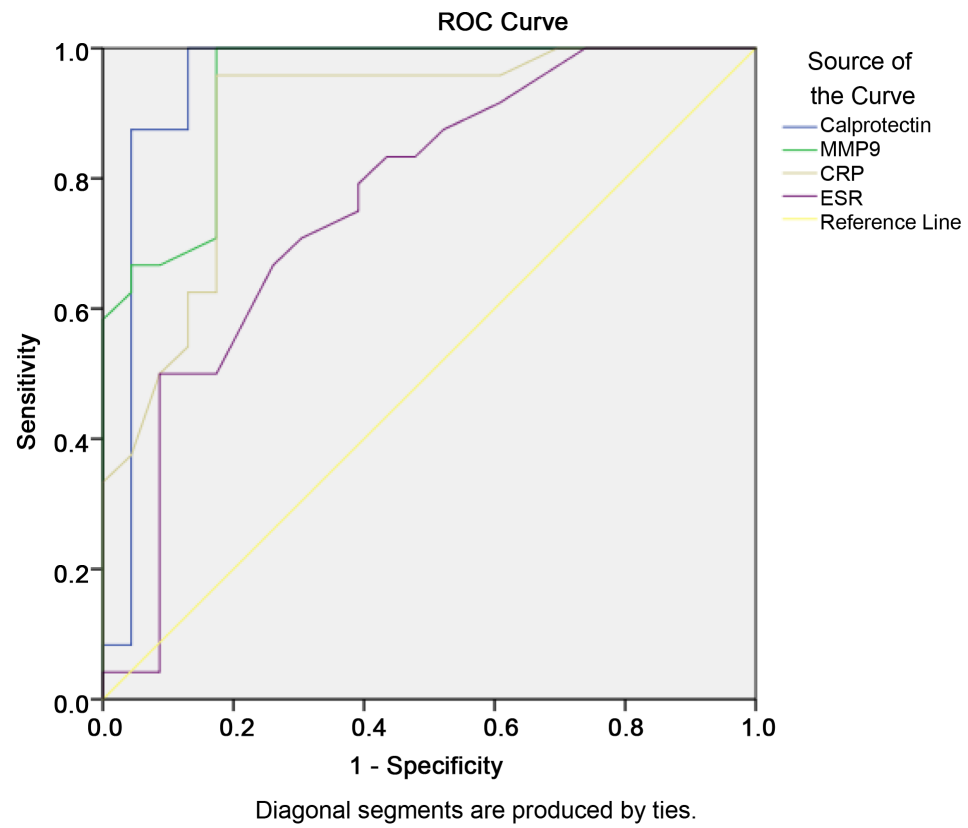

Figure 3. ROC curve analysis on the abilities of fecal calprotectin, serum MMP-9, CRP and ESR to differentiate between active and inactive UC. The ROC analysis on the fecal calprotectin showed that a cut-off point of $240 \mu \mathrm{g} / \mathrm{g}$ had a $100 \%$ sensitivity and a $86.9 \%$ specificity for making a differentiation between active UC and inactive UC. As regard to serum MMP-9, a cutoff value of $4.5 \mathrm{ng} / \mathrm{ml}$ had $100 \%$ sensitivity and a $82.6 \%$ specificity to differentiate between active and inactive UC.

Fecal calprotectin (FC) is a calcium-binding protein derived predominantly from granulocytes migrating via intestinal wall [27] [28] which constitutes $60 \%$ of cytosolic protein in human neutrophils [29] and about $5 \%$ of the total protein 
[30]. Several clinical studies report the association between FC and the severity of intestinal inflammation [4] [31]. Accordingly, the level of FC is proportional to UC activity, and it can reliably distinguish active versus inactive disease [4] [32].

Expression of metalloproteinases is altered in diseases with inflammatory background [33] [34]. Many studies point to MMP-9 as a key enzyme engaged in the degradation of alimentary tract tissues in the course of IBD [18] [35]. MMP-9 is also involved in the shedding and activation of biologically active molecules, which further perpetuates pathological processes observed in IBD [35] and renders MMP-9 an interesting diagnostic and therapeutic target.

Our study results revealed that fecal calprotectin level was significantly higher in active than inactive or control group with strong positive correlation with the activity of ulcerative colitis determined by Mayo score. This was in accordance with Xiang et al. who reported that fecal calprotectin concentration in the patients with active UC was significantly higher than that in the inactive UC and in the controls [36].

Also, we found that serum MMP-9 concentration was significantly higher in patients with active ulcerative colitis than in patients with inactive state or in the control group. Serum MMP-9 levels showed strong positive correlation with activity of ulcerative colitis. Our results agreed with Lakatos et al. who noted that serum concentrations of MMP-9 were higher in UC patients compared to controls and correlated well with the disease activity [37]. Also, in agreement with our results, Malgorzata et al. reported that MMP-9 concentrations in active UC were significantly higher not only than those detected in controls but also with respect to concentrations measured in patients with inactive forms [38].

We found in the current study that fecal calprotectin with a cutoff value of 240 $\mu \mathrm{g} / \mathrm{g}$ had $100 \%$ sensitivity and $86.9 \%$ specificity for differentiating active ulcerative colitis from inactive disease and that a serum MMP-9 level of $4.5 \mathrm{ng} / \mathrm{ml}$ had $100 \%$ sensitivity and $82.6 \%$ specificity to differentiate active state of ulcerative colitis from inactive disease. In conclusion, fecal calprotectin and serum MMP-9 can be useful as possible supportive markers allowing differentiation between active and inactive forms of UC.

\section{References}

[1] Torres, J., Billioud, V., Sachar, D.B., Peyrin-Biroulet, L. and Colombel, J.-F. (2012) Ulcerative Colitis as a Progressive Disease: The Forgotten Evidence. Inflammatory Bowel Diseases, 18, 1356-1363. https://doi.org/10.1002/ibd.22839

[2] Annese, V., Daperno, M., Rutter, M.D., et al. (2013) European Evidence Based Consensus for Endoscopy in Inflammatory Bowel Disease. Journal of Crohn's and Colitis, 7, 982-1018. https://doi.org/10.1016/j.crohns.2013.09.016

[3] Angriman, I., Scarpa, M., D’Inca, R., et al. (2007) Enzymes in Feces: Useful Markers of Chronic Inflammatory Bowel Disease. Clinica Chimica Acta, 381, 63-68. https://doi.org/10.1016/j.cca.2007.02.025

[4] Schoepfer, A.M., Beglinger, C., Straumann, A., et al. (2009) Ulcerative Colitis: Correlation of the Rachmilewitz Endoscopic Activity Index with Fecal Calprotectin, Clinical Activity, C-Reactive Protein, and Blood Leukocytes. Inflammatory Bowel 
Diseases, 15, 1851-1858. https://doi.org/10.1002/ibd.20986

[5] Travis, S.P., Schnell, D., Krzeski, P., et al. (2013) Reliability and Initial Validation of the Ulcerative Colitis Endoscopic Index of Severity. Gastroenterology, 145, 987-995. https://doi.org/10.1053/j.gastro.2013.07.024

[6] Walsh, A.J., Ghosh, A., Brain, A.O., et al. (2014) Comparing Disease Activity Indices in Ulcerative Colitis. Journal of Crohn's and Colitis, 8, 318-325. https://doi.org/10.1016/j.crohns.2013.09.010

[7] Nikolaus, S. and Schreiber, S. (2007) Diagnostics of Inflammatory Bowel Disease. Gastroenterology, 133, 1670-1689. https://doi.org/10.1053/j.gastro.2007.09.001

[8] Dubinsky, M.C., Ofman, J.J., Urman, M., Targan, S.R. and Seidman, E.G. (2001) Clinical Utility of Serodiagnostic Testing in Suspected Pediatric Inflammatory Bowel Disease. American Journal of Gastroenterology, 96, 758-765. https://doi.org/10.1111/j.1572-0241.2001.03618.x

[9] Desai, D., Faubion, W.A. and Sandborn, W.J. (2007) Review Article: Biological Activity Markers in Inflammatory Bowel Disease. Alimentary Pharmacology \& Therapeutics, 25, 247-255. https://doi.org/10.1111/j.1365-2036.2006.03184.x

[10] Tibble, J.A., Sigthorsson, G., Bridger, S., Fagerthol, M.K. and Bjarnason, I. (2000) Surrogate Markers of Intestinal Inflammation Are Predictive of Relapse in Patients with Inflammatory Bowel Disease. Gastroenterology, 119, 15-22. https://doi.org/10.1053/gast.2000.8523

[11] Bitton, A., Peppercorn, M.A., Antonioli, D.A., et al. (2001) Clinical, Biological, and Histologic Parameters as Predictors of Relapse in Ulcerative Colitis. Gastroenterology, 120, 13-20. https://doi.org/10.1053/gast.2001.20912

[12] Sutherland, A.D., Gearry, R.B. and Frizelle, F.A. (2008) Review of Fecal Biomarkers in Inflammatory Bowel Disease. Diseases of the Colon \& Rectum, 51, 1283-1291. https://doi.org/10.1007/s10350-008-9310-8

[13] Dale, I., Brandtzaeg, P., Fagerhol, M.K. and Scott, H. (1985) Distribution of a New Myelomonocytic Antigen (L1) in Human Peripheral Blood Leukocytes. Immunofluorescence and Immunoperoxidase Staining Features in Comparison with Lysozyme and Lactoferrin. American Journal of Clinical Pathology, 84, 24-34. https://doi.org/10.1093/ajcp/84.1.24

[14] Roseth, A.G., Kristinsson, J., Fagerhol, M.K., Schjonsby, H., Aadland, E., Nygaard, K. and Roald, B. (1993) Faecal Calprotectin: A Novel Test for the Diagnosis of Colorectal Cancer? Scandinavian Journal of Gastroenterology, 28, 1073-1076. https://doi.org/10.3109/00365529309098312

[15] Johne, B., Fagerhol, M.K., Lyberg, T., Prydz, H., Brandtzaeg, P., Naess-Andresen, C.F. and Dale, I. (1997) Functional and Clinical Aspects of the Myelomonocyte Protein Calprotectin. Molecular Pathology, 50, 113-123. https://doi.org/10.1136/mp.50.3.113

[16] Roseth, A.G., Fagerhol, M.K., Aadland, E. and Schjonsby, H. (1992) Assessment of the Neutrophil Dominating Calprotectin in Feces: A Methodologic Study. Scandinavian Journal of Gastroenterology, 27, 793-798. https://doi.org/10.3109/00365529209011186

[17] Egeblad, M. and Werb, Z. (2002) New Functions for the Matrix Metalloproteinases in Cancer Progression. Nature Reviews Cancer, 2, 161-174. https://doi.org/10.1053/gast.2000.8523

[18] Santana, A., Medina, C., Paz-Cabrera, M.C., et al. (2006) Attenuation of Dextran Sodium Sulphate Induced Colitis in Matrix Metalloproteinase-9 Deficient Mice. World Journal of Gastroenterology, 12, 6464-6472. 
https://doi.org/10.3748/wjg.v12.i40.6464

[19] Gan, X., Wong, B., Wright, S.D. and Cai, T.-Q. (2001) Production of Matrix Metalloproteinase- 9 in CaCO-2 Cells in Response to Inflammatory Stimuli. Journal of Interferon \& Cytokine Research, 21, 93-98. https://doi.org/10.1089/107999001750069953

[20] Castaneda, F.E., Walia, B., Vijay-Kumar, M., et al. (2005) Targeted Deletion of Metalloproteinase 9 Attenuates Experimental Colitis in Mice: Central Role of Epithelial-Derived MMP. Gastroenterology, 129, 1991-2008. https://doi.org/10.1053/j.gastro.2005.09.017

[21] Schroeder, K.W., Tremaine, W.J. and Ilstrup, D.M. (1987) Coated Oral 5-Aminosalicylic Acid Therapy for Mildly to Moderately Active Ulcerative Colitis: A Randomized Study. New England Journal of Medicine, 317, 1625-1629. https://doi.org/10.1056/NEJM198712243172603

[22] Ordas, I., Eckmann, L., Talamini, M., Baumgart, D.C. and Sandborn, W.J. (2012) Ulcerative Colitis. The Lancet, 380, 1606-1619. https://doi.org/10.1016/S0140-6736(12)60150-0

[23] Talley, N.J., Abreu, M.T., Achkar, J.P., et al. (2011) An Evidence-Based Systematic Review on Medical Therapies for Inflammatory Bowel Disease. The American Journal of Gastroenterology, 106, S2-S25. https://doi.org/10.1038/ajg.2011.58

[24] Abraham, C. and Cho, J.H. (2009) Inflammatory Bowel Disease. New England Journal of Medicine, 361, 2066-2078. https://doi.org/10.1056/NEJMra0804647

[25] Molodecky, N.A., Soon, I.S., Rabi, D.M., et al. (2012) Increasing Incidence and Prevalence of the Inflammatory Bowel Diseases with Time, Based on Systematic Review. Gastroenterology, 142, 46-54, e42. https://doi.org/10.1053/j.gastro.2011.10.001

[26] Dignass, A., Eliakim, R., Magro, F., et al. (2012) Second European Evidence-Based Consensus on the Diagnosis and Management of Ulcerative Colitis Part 1: Definitions and Diagnosis. Journal of Croh's and Colitis, 6, 965-990. https://doi.org/10.1016/j.crohns.2012.09.003

[27] Bjerke, K., Halstensen, T.S., Jahnsen, F., Pulford, K. and Brandtzaeg, P. (1993) Distribution of Macrophages and Granulocytes Expressing L1 Protein (Calprotectin) in Human Peyer's Patches Compared with Normal Ileal Lamina Propria and Mesenteric Lymph Nodes. Gut, 34, 1357-1363. https://doi.org/10.1136/gut.34.10.1357

[28] Costa, F., Mumolo, M.G., Ceccarelli, L., et al. (2005) Calprotectin Is a Stronger Predictive Marker of Relapse in Ulcerative Colitis than in Crohn's Disease. Gut, 54, 364-368. https://doi.org/10.1136/gut.2004.043406

[29] Sands, B.E. (2015) Biomarkers of Inflammation in Inflammatory Bowel Disease. Gastroenterology, 149, 1275-1285. https://doi.org/10.1053/j.gastro.2015.07.003

[30] Konikoff, M.R. and Denson, L.A. (2006) Role of Fecal Calprotectin as a Biomarker of Intestinal Inflammation in Inflammatory Bowel Disease. Inflammatory Bowel Diseases, 12, 524-534. https://doi.org/10.1097/00054725-200606000-00013

[31] Menees, S.B., Powell, C., Kurlander, J., Goel, A. and Chey, W.D. (2015) A Meta-Analysis of the Utility of C-Reactive Protein, Erythrocyte Sedimentation Rate, Fecal Calprotectin, and Fecal Lactoferrin to Exclude Inflammatory Bowel Disease in Adults with IBS. The American Journal of Gastroenterology, 110, 444-454. https://doi.org/10.1038/ajg.2015.6

[32] Garcia-Sanchez, V., Iglesias-Flores, E., Gonzalez, R., et al. (2010) Does Fecal Calprotectin Predict Relapse in Patients with Crohn's Disease and Ulcerative Colitis? Journal of Crohn's and Colitis, 4, 144-152.

https://doi.org/10.1016/j.crohns.2009.09.008 
[33] Tchetverikov, I., Lard, L.R., DeGroot, J., et al. (2003) Matrix Metalloproteinases-3, $-8,-9$ as Markers of Disease Activity and Joint Damage Progression in Early Rheumatoid Arthritis. Annals of the Rheumatic Diseases, 62, 1094-1099. https://doi.org/10.1136/ard.62.11.1094

[34] Meijer, M.J.W., Mieremet-Ooms, M.A.C., van der Zon, A.M., et al. (2007) Increased Mucosal Matrix Metalloproteinase-1, -2, -3 and -9 Activity in Patients with Inflammatory Bowel Disease and the Relation with Crohn's Disease Phenotype. Digestive and Liver Disease, 39, 733-739. https://doi.org/10.1016/j.dld.2007.05.010

[35] Ravi, A., Garg, P. and Sitaraman, S.V. (2007) Matrix Metalloproteinases in Inflammatory Bowel Disease: Boon or a Bane? Inflammatory Bowel Diseases, 13, 97-107. https://doi.org/10.1002/ibd.20011

[36] Xiang, J.Y., Ouyang, Q., Li, G.D. and Xiao, N.P. (2008) Clinical Value of Fecal Calprotectin in Determining Disease Activity of Ulcerative Colitis. World Journal of Gastroenterology, 14, 53-57.

[37] Lakatos, G., Hritz, I., Varga, M.Z., et al. (2012) The Impact of Matrix Metalloproteinases and Their Tissue Inhibitors in Inflammatory Bowel Diseases. Digestive Diseases, 30, 289-295.

[38] Matusiewicz, M., Neubauer, K., Mierzchala-Pasierb, M., Gamian, A. and Krzystek-Korpacka, M. (2014) Matrix Metalloproteinase-9: Its Interplay with Angiogenic Factors in Inflammatory Bowel Diseases. Disease Markers, 2014, Article ID: 643645. 